\title{
Valuación de Bienes de Uso en el Marco de las Nuevas Normas Contables Profesionales
}

C.P.N. B eatriz Brozzú (1)

C.P.N. Nestor G. Haquín (2)

(1) Docente adjunto -

Cátedra de Contabilidad Básica, Facultad de Ciencias Económicas, Universidad Nacional del Litoral.

(2) Mgter. Adm. Emp. Docente adjunto Cátedra de Contabilidad Básica, Facultad de Ciencias Económicas, Universidad Nacional del Litoral. E-mail: nghaquin@ arnet.com.ar
Palabras claves

- Bienes de Uso

- Valores Corrientes

- Valores Históricos

- Revaluación

- Valor Real
Key words

- Property, Plant,

Equipment

- Current Values

- Historical Values

- Revaluation

- Fair Value.

\section{Resumen}

Respecto a la valuación de los Bienes de Uso el abandono de los valores corrientes, reemplazado por valores históricos, sacrifica los requisitos de aproximación a la realidad, verificabilidad y confiabilidad de la información.

Al mismo tiempo, se contradice con Normas Internacionales de Contabilidad (IAS) hacia las que supuestamente buscaba armonizar, ya que éstas (IAS 16) admiten revalorizaciones y desvalorizaciones, con énfasis en mostrar, en todo momento, el fair value de los Bienes de Uso.

\section{Abstract}

As regards as Property, Plants and Equipment's fair value FACPCE New Accounting Standards (16 to 19) replaces current values by historical values. In doing so it sacrifices the essential informational qualities and also disagrees with the IAS, since IAS 16 allows revaluations and points out the need of showing fair value at any moment. 